\title{
НЕДЕЙСТВИТЕЛЬНОСТЬ ИСПОЛНИТЕЛЬНЫХ ДОКУМЕНТОВ И ОСНОВАНИЯ ПРИЗНАНИЯ ИХ ТАКОВЫМИ
}

\begin{abstract}
АНнотАЦИЯ. В статье на основания цивилистического учения о недействительности сделки обоснованы критерии признания недействительными исполнительных документов, ими являются: несоблюдение формы и содержания, предусмотренных законом для исполнительных документов, отсутствие в них конституирующего признака - предписания принудительного исполнения, неправосубъектность лиц, выдавших исполнительный документ, сторон исполнительного производства. Основанием для признания недействительным исполнительного документа также названо наличие в нем требования совершения действия, которое не может быть исполнено (невероятное действие). Несовпадение воли и волеизъявления названо исключительным основанием для признания исполнительного документа недействительным. Процессуальные основания для признания исполнительных документов недействительными являются: их несоответствие закону, иному ненормативному акту; нарушение ими прав и законных интересов граждан и организаций; создание препятствий к осуществлению гражданином и иных лиц их прав и свобод; незаконное возложение на гражданина, иное лицо какой-либо обязанности, незаконное привлечение гражданина, иного лица к ответственности. КЛЮчЕВЫЕ СЛОВА. Исполнительный документ; недействительность исполнительного документа; основания недействительности исполнительного документа; принудительное исполнение.
\end{abstract}

ИНФОРМАЦИЯ О СТАТЬЕ. Дата поступления 5 сентября 2016 г.; дата принятия к печати 19 октября 2016 г.; дата онлайн-размещения 30 ноября 2016 г.

E. A. Gnatko

Baikal State University, Irkutsk, Russian Federation

\section{INVALIDITY OF EXECUTIVE DOCUMENTS AND GROUNDS OF RECOGNIZING THEM AS SUCH}

\begin{abstract}
On the basis of the civilized teaching about invalidity of the transaction, the article substantiates the criteria for admitting invalidity of executive documents, which can be the following: failure to comply with the form and content provided by law for executive documents, absence in them a constitutive feature - law enforcement compliance notice, non-legal provision of the persons having issued the executive document, the parties of enforcement proceedings. The ground for admitting invalidity of the executive document can also be caused by presence in it a demand to do an act which can not be executed (improbable action). The discrepancy between the will and expression of the will is called an exclusive ground for admitting the executive document invalid. Procedural grounds for admitting executive documents invalid are: their inconformity with law, other non-normative act; their violation of right and legal interests of citizens and organizations; obstructiveness to implementing citizens' or other persons' rights and freedoms; illegal placing of certain duty upon a citizen or another person, illegal bringing a citizen on another person to responsibility.

KEYWORDS. Executive document; invalidity of executive document; grounds of invalidity of executive document; enforcement.

ARTICLE INFO. Received September 5, 2016; accepted October 19, 2016; available online November 30, 2016.
\end{abstract}

(C) E. А. Гнатко, 2016

\section{Baikal Research Journal}


Статья 43 Федерального закона «Об исполнительном производстве» от 2 октября 2007 г. № 229-Ф3 ${ }^{1}$ (далее - Закон об исполнительном производстве) указывает на такое основание для прекращения исполнительного производства как признание недействительным исполнительного документа, на основании которого возбуждалось исполнительное производство. Однако Закон не предусматривает критериев признания исполнительного документа недействительным, кроме того, остается открытым вопрос, в полномочие каких субъектов входит право (или обязанность?) признания исполнительных документов недействительными. В такой ситуации становится невозможным соблюдение требований естественного права, обеспечение прав личности и гарантий их конституционной правоспособности [1].

Исполнительные документы - это индивидуальные акты [2, с. 41-60), акты индивидуального правового регулирования [3, с. 11-27], юридические факты [4, с. 49], ненормативные правовые акты (решения государственных органов, органов местного самоуправления, их должностных лиц [5, с. 330]), составленные в установленной законом форме с соблюдением предъявляемых к ним требований [6, с. 128], которые представляют собой предписание реализовать прописанное в них требование в порядке исполнительного производства [7, с. 43]. Представляется, признавать исполнительные документы, столь сложное и многогранное правовое явление, недействительными вправе только судебные органы согласно ст. 120 Конституции $Р \Phi^{2}$, в соответствии с которой суд принимает решение, если установит несоответствие акта государственного или иного органа закону.

Арбитражный процесс, административный процесс по Кодексу административного судопроизводства РФ ${ }^{3}$ (КАС РФ) не предусматривают таких категорий дел, как «признание ненормативного акта недействительным», во всех случаях речь идет об оспаривании ненормативных правовых актов, решений, действий (бездействия) органов государственной власти, местного самоуправления, их должностных лиц. При этом в ст. 201 Арбитражный процессуальный кодекс РФ ${ }^{4}$ (АПК РФ) указано, что арбитражный суд, установив, что ненормативный правовой акт не соответствует закону, другому нормативному акту, нарушает права и законные интересы заявителя, принимает решение о признании его недействительным, из чего следует, что критериями недействительности ненормативных актов по АПК РФ являются: его несоответствие закону или иному ненормативному акту; нарушением им прав и законных интересов обратившегося в суд лица.

Статья 255 Гражданский процессуальный кодекс РФ $\Phi^{5}$ (ГПК РФ), регулирующая правоотношения в сфере оспаривания ненормативных актов в судах общей юрисдикции до вступления в законную силу КАС РФ, содержала следующие критерии для признания ненормативного акта недействительным:

- нарушение прав и свобод гражданина;

- создание препятствий к осуществлению гражданином его прав и свобод;

- незаконное возложение на гражданина какой-либо обязанности, незаконное привлечение гражданина к ответственности [8, с. 517].

${ }^{1}$ Об исполнительном производстве : федер. закон РФ от 2 окт. 2007 г. № 229-ФЗ // Собрание законодательства РФ. 2007. № 41. Ст. 4849.

2 Конституция Российской Федерации: принята всенар. голосованием 12 дек. 1993 г. // Российская газета. - 1993. - 25 дек.

${ }^{3}$ Кодекс административного судопроизводства Российской Федерации : федер. закон от 8 марта 2015 г. № 21-Ф3 // Собрание законодательства РФ. 2015. № 10. Ст. 1391.

${ }^{4}$ Арбитражный процессуальный кодекс Российской Федерации : федер. закон от 24 июля 2002 г. № 95-ФЗ // Там же. 2002. № 30. Ст. 3012.

${ }^{5}$ Гражданский процессуальный кодекс Российской Федерации : федер. закон от 14 нояб. 2002 г. № 138-Ф3 // Там же. № 46. Ст. 4532.

\section{Baikal Research Journal}


КАС РФ требует от правоприменителей удовлетворять либо отказывать в заявленных требованиях о признании решений незаконными и обязывать административного ответчика устранять нарушения прав, законных интересов истца или препятствия к осуществлению прав, свобод, законных интересов (ст. 227 КАС РФ). Основаниями для признания решений незаконными согласно ст. 218 КАС РФ являются: нарушение или оспаривание прав, свобод, законных интересов, создание препятствий к осуществлению прав, свобод, реализации законных интересов, незаконное возложение обязанностей. В случае если в суд обращаются органы государственной власти, Уполномоченный по правам человека РФ, в субъектах, то основание для признания решений незаконными является, кроме перечисленных, их несоответствие нормативному правовому акту. Однако постановление Пленума ВС РФ «О применении судами законодательства при рассмотрении некоторых вопросов, возникающих в ходе исполнительного производства» от 17 ноября 2015 г. № $50^{6}$ прямо указывает на рассмотрение таких категорий дел в порядке искового судопроизводства, поскольку от разрешения требований зависит определение гражданских прав и обязанностей сторон исполнительного производства, о чем и свидетельствует судебная практика.

Гражданский кодекс $Р \Phi^{7}$ (ГК РФ) в ст. 13 указывает на возможность признания недействительным ненормативного акта государственного органа, местного самоуправления в случае, если он не соответствует закону, иным правовым актам, нарушает права, охраняемые законом интересы лица.

Исходя из вышеперечисленных положений, возможен следующий вывод о том, какие основания предусмотрены российским законодательством для признания ненормативного акта недействительным:

- его несоответствие закону, иному ненормативному акту;

- нарушение им прав и законных интересов граждан и организаций;

- создание препятствий к осуществлению гражданином и иных лиц их прав и свобод;

- незаконное возложение на гражданина, иное лицо какой-либо обязанности, незаконное привлечение гражданина, иного лица к ответственности.

Причем, только первое основание - несоответствие закону - может быть материальным, остальные три указывают на необходимость судебной защиты и восстановления попранных прав, то есть являются процессуальными.

С другой стороны, представляется, что оценить понятие «недействительный» возможно с точки зрения гражданского права, где оно тщательно разработано применительно к сделкам, тем более, учеными-правоведами признано, что и сделки, и ненормативные акты, каковыми являются исполнительные документы, есть юридические факты.

Условиями действительности сделок традиционно признают следующие: законность содержания, способность ее субъектов к участию в сделке, соответствие воли и волеизъявления, соблюдение формы сделки [9, с. 137]. Законность содержания - это ее соответствие требованиям закона, субъекты сделки должны быть правосубъектными [10, с. 6], обладать дееспособностью [11, с. 15]. Действительность сделки предполагает совпадение воли и волеизъявления: несоответствие действительными желаниями и выражением их вовне может быть основанием для признания сделки недействительной, при этом упречность (дефектность) воли

${ }^{6}$ О применении судами законодательства при рассмотрении некоторых вопросов, возникающих в ходе исполнительного производства : постановление Пленума ВС РФ от 17 ноября 2015 г. № 50 // Российская газета. 2015. 30 нояб.

${ }^{7}$ Гражданский кодекс Российской Федерации : федер. закон от 30 нояб. 1994 г. № 51-Ф3 // Собрание законодательства РФ. 1994. № 32. Ст. 3301.

\section{Baikal Research Journal}

электронный научный журнал Байкальского государственного университета 
[12, с. 69], сформированная под влиянием угрозы, насилия, тоже является основанием для признания недействительности сделок [13, с. 13]. Форма сделок может быть устной и письменной, простой и нотариальной.

Исходя из изложенного, представляется, что теория недействительности исполнительных документов должна выглядеть следующим образом. Как указывалось нами выше, ко всем исполнительным документам должны предъявляться законом единые требования, кроме специальных, предусмотренных соответствующим законодательством. Единые требования относятся в первую очередь к форме исполнительного документа (простая письменная, в электронном виде), следовательно, основанием для признания исполнительного документа недействительным является несоблюдение предусмотренной законом формы документа, а также несоответствие наименования документа перечню исполнительных документов, предусмотренному Законом.

Кроме того, основанием для признания исполнительного документа недействительным станет несоблюдение требований к его содержанию, то есть незаконность содержания, а именно: отсутствие сведений о лицах, выдавших исполнительный документ, указания на нормы закона, дающих права этим лицам выдавать исполнительные документы, отсутствие сведений о должнике и взыскателе: фамилия, имя, отчество, место жительства по регистрации и фактическое, дата и место рождения (для должника - место работы и должность) - для физических лиц, гражданско-правовая форма, полное фирменное наименование, юридический адрес, фактическое место нахождения - для юридических лиц. Незаконность содержания исполнительного документа также будет проявляться в отсутствии сведений о вступлении в законную силу, сроке предъявления ко взысканию и порядке отмены.

Обоснованность вышеназванных выводов подтверждает судебная практика. Белгородский областной суд вынес апелляционное определение, в котором признал недействительным исполнительный лист, выданный Старооскольским городским судом, поскольку в нем указан как должник гражданин В. П. Помеляйко, а не организацияя, чьей главой являлся гражданин В. П. Помеляйко, который как представитель должника - организации заключил мировое соглашение со взыскателем. Суд указал в своих выводах, что выдача судом исполнительного документа не соответствует положениям ст. 13, 49 Закона об исполнительном производстве, устанавливающим требования к исполнительному документу, а также определяющими стороны исполнительного производства ${ }^{8}$.

Выше мы указывали, что каждый исполнительный документ должен содержать в себе конституирующий признак - наличие предписания принудительного исполнения, т. е. указание на произведение конкретного действия помимо воли должника и с использованием принуждения или отказа от его произведения. Представляется, что отсутствие этого обязательного признака в конкретном исполнительном документе означает, что этот исполнительный документ недействителен, поскольку в нем присутствует порок содержания. Также недействительным должен признаваться исполнительный документ, который содержит в себе требование совершения действия, которое не может быть исполнено (невероятное действие). Так, определением Арбитражного суда Нижегородской области по делу № A43-19656/2015 было утверждено мировое соглашение, в которое вошло следующее условие: «Ответчик также обещает возносить молитвы о здравии раба Божиего Арсеньева Ивана Михайловича и раба Божиего Лепустина Сергея Александровича, их семей и благополучии во всех их благих делах и на-

\footnotetext{
${ }^{8}$ Судебные решения. РФ. URL: http://судебныерешения.pф/bsr/case/1715248.
}

\section{Baikal Research Journal}


чинаниях" ${ }^{9}$. Сторона мирового соглашения при неисполнении условий соглашения другой стороной вправе просить суд о выдаче ему исполнительного листа на принудительное исполнение условий мирового соглашения, в связи с чем истцы, если удостоверятся, что ответчик не выполняет условий соглашения, вправе просить о принудительном их исполнении РО «Нижегородская епархия Русской православной церкви (Московский патриархат)», что, исходя из сути указанных отношений невозможно. Постановление Пленума ВС РФ «О применении судами законодательства при рассмотрении некоторых вопросов, возникающих в ходе исполнительного производства» от 17 ноября 2015 г. № 50 прямо указывает, что исполнительные листы, не содержащие предписаний передать денежные средства или иное имущество, совершить либо воздержаться от совершения определенных действий (в случаях признания судом права на имущество, понуждения к заключению договора, определению порядка пользования имуществом), судом не выдаются. Представляется, если они все же были выданы, то могут быть в судебном порядке признаны недействительными.

Несоблюдением формы и содержания исполнительного документа станет и невыполнение требований к нему, предъявляемых специальным законодательством: в случае исполнительных надписей - Основами законодательства о нотариате, удостоверений комиссий по трудовым спорам - Трудовым кодексом РФ, и др.

Кроме несоблюдения формы и содержания, основанием для признания исполнительных документов недействительными является неправосубъектность лиц, либо выдавших исполнительный документ, либо тех, в отношении кого он выдан. В случае если исполнительные документы выдаются судами, государственными и муниципальными органами, нотариусами уместнее говорить не о дееспособности, а о правовом статусе указанных лиц; органы и их должностные лица должны быть уполномочены на выдачу исполнительных документов законом, созданы и назначены при соблюдении закона и специальными ненормативными актами. Все иные участники исполнительных правоотношений должны быть право-, дееспособны; физические лица должны достичь соответствующего возраста, не должны быть признаны недееспособными, юридические - созданы и зарегистрированы в соответствии с законом. Комиссия по трудовым спорам, способная выдавать исполнительный документ - удостоверение, правосубъектна в том случае, если была создана и действовала в соответствии с положениями Трудового кодекса РФ.

Действительность сделки предполагает, указано было выше, совпадение воли и волеизъявления. Представляется, что к большей части исполнительных документов, в настоящее время предусмотренных законодательством Российской Федерации, такой признак не относится: государственные органы, муниципалитет не вправе иметь иной воли, какая предоставлена им законом (любой отход от закона - юрисдикция уголовного законодательства). Вместе с тем в перечне российских исполнительных документов содержится нотариально удостоверенное соглашение об уплате алиментов. Как выше нами было выяснено, данное соглашение - это гражданско-правовой договор, сделка, которая может не соответствовать действительным желаниям ее сторон и выражением воли вовне. Кроме того, при заключении такого договора может возникнуть и дефектность воли, которая может сформироваться под влиянием насилия либо угрозы. Из чего следует, что основание для признания сделки недействительной - несовпадение воли и волеизъявления - является также основанием для признания исполнительного документа недействительным, но скорее исключением, чем регулярным правилом.

${ }^{9}$ URL: http://kad.arbitr.ru/Card/cf103e93-dc0e-4190-8121-287e06b8c732.

\section{Baikal Research Journal}

электронный научный журнал Байкальского государственного университета 


\section{Список использованной литературы}

1. Амосов С. М. Судебное познание в арбитражном процессе : автореф. дис. ... д-ра юрид. наук : 12.00.15 / С. М. Амосов. - М., 2004. - 43 с.

2. Минникес И. А. Индивидуальное правовое регулирование: понятие, правотворческая деятельность, правовое акты / И. А. Минникес. - Иркутск : Ин-т законодательства и правовой информ. им. М. М. Сперанского, 2009. - 72 с.

3. Некрасов С. Ю. Выход суда за пределы заявленных требований в цивилистическом процессе при разрешении споров, возникающих из правоотношений, основанных на юридических составах : монография / С. Ю. Некрасов. - М. : Изд. дом Шумиловой И. И., 2014. -200 c.

4. Зинченко С. А. Юридические факты в механизме правового регулирования / С. А. Зинченко. - М. : Волтерс Клувер, 2007. - 144 с.

5. Гражданское процессуальное право / под ред. М. С. Шакарян. - М. : Проспект, 2004. - $580 \mathrm{c.}$

6. Гуреев В. А. Исполнительное производство : учебник / В. А. Гуреев, В. В. Гущин. М. : Юрайт, 2012. - 560 с.

7. Гнатко Е. А. Исполнительное производство: обобщающий курс лекций, статьи / Е. А. Гнатко. - Иркутск : Оттиск, 2015. - 96 с.

8. Научно-практический комментарий к Гражданскому процессуальному кодексу Российской Федерации / под ред. В. М. ЖЖуйкова, В. К. Пучинского, М. К. Треушникова. М. : Городец, 2003. - 1088 с.

9. Гражданское право : учебник : в 2 т. / под ред. Е. А. Суханова. - М. : БЕК, 1994. T. 1. - 384 c.

10. Козлова Н. В. Правосубъектность юридического лица / Н. В. Козлова. - М. : Статут, 2005. - 480 с.

11. Тариканов Д. В. Юридическая личность коммерческих организаций в гражданском праве России / Д. В. Тариканов. - М. : Статут, 2007. - 256 с.

12. Тузов Д. О. Ничтожность и оспоримость юридической сделки: пандектное учение и современное право / Д. О. Тузов. - М. : Статут, 2006. - 208 с.

13. Комментарий части первой Гражданского кодекса Российской Федерации для предпринимателей / М. И. Брагинский, В. В. Витрянский, В. П. Звеков, Е. А. Суханов, К. Б. Ярошенко. - М. : Правовая культура, 1995. - 480 с.

\section{References}

1. Amosov S. M. Sudebnoe poznanie v arbitrazhnom protsesse. Avtoref. Dokt. Diss. [Fact-finding in arbitrary procedure. Doct. Diss. Thesis]. Moscow, 2004. 43 p.

2. Minnikes I. A. Individual'noe pravovoe regulirovanie: ponyatie, pravotvorcheskaya deyatel'nost', pravovoe akty [Individual legal regulation: concept, lawmaking activity, legal acts]. Irkutsk, Institute of Legislation and Legal Information M. M. Speranskii Publ., 2009. 72 p.

3. Nekrasov S. Yu. Vykhod suda za predely zayavlennykh trebovanii $v$ tsivilisticheskom protsesse pri razreshenii sporov, voznikayushchikh iz pravootnoshenii, osnovannykh na yuridicheskikh sostavakh [Court stepping over the limits of asserted claims in the civilized procedure in settling disputes arising from legal relations bases on set of facts]. Moscow, Shumilova I. I. Publ., 2014. 200 p.

4. Zinchenko S. A. Yuridicheskie fakty $v$ mekhanizme pravovogo regulirovaniya [Juridical facts in mechanism of legal regulation]. Moscow, Volters Kluver Publ., 2007. 144 p.

5. Shakaryan M. S. (ed.). Grazhdanskoe protsessual'noe pravo [Civil Procedural Law]. Moscow, Prospekt Publ., 2004. 580 p.

6. Gureyev V. A., Gushchin V. V. Ispolnitel'noe proizvodstvo [Enforcement proceeding]. Moscow, Yurait Publ., 2012. 560 p.

7. Gnatko E. A. Ispolnitel'noe proizvodstvo: obobshchayushchii kurs lektsii, stat'i [Enforcement proceeding: a summarizing course of lectures, articles]. Irkutsk, Ottisk Publ., 2015. 96 p.

8. Zhuikov V. M., Puchinsky V. K., Treushnikov M. K. (eds). Nauchno-prakticheskii kommentarii $k$ Grazhdanskomu protsessual'nomu kodeksu Rossiiskoi Federatsii [Science and Practice Comment to Civil Procedural Code of the Russian Federation]. Moscow, Gorodets Publ., 2003. $1088 \mathrm{p}$.

\section{Baikal Research Journal}


9. Sukhanov E. A. (ed.). Grazhdanskoe pravo [Civil Law]. Moscow, BEK Publ., 1994. Vol. 1. 384 p.

10. Kozlova N. V. Pravosub"ektnost' yuridicheskogo litsa [Legal capacity of the juridical personality]. Moscow, Statut Publ., 2005. 480 p.

11. Tarikanov D. V. Yuridicheskaya lichnost' kommercheskikh organizatsii v grazhdanskom prave Rossii [Juridical personality of commercial organizations in Russia's Civil Law]. Moscow, Statut Publ., 2007. 256 p.

12. Tuzov D. O. Nichtozhnost' i osporimost' yuridicheskoi sdelki: pandektnoe uchenie $i$ sovremennoe parvo [Nihility and voidance of a legal transaction: doctrine of pandects and modern law]. Moscow, Statut Publ., 2006. 208 p.

13. Braginsky M. I., Vitryansky V. V., Zvekov V. P., Sukhanov E. A., Yaroshenko K. B. Kommentarii chasti pervoi Grazhdanskogo kodeksa Rossiiskoi Federatsii dlya predprinimatelei [Comment of Part One of the Civil Code of the Russian Federation for Businessmen]. Moscow, Pravovaya kul'tura Publ., 1995. 480 p.

\section{Информация об авторе}

Гнатко Елена Александровна - старший преподаватель, кафедра гражданского права и процесса, Байкальский государственный университет, 664003, г. Иркутск, ул. Ленина, 11, e-mail: gnatko.ea@gmail.com.

\section{Author}

Elena A. Gnatko - Senior Lecturer, Chair of Civil Law and Procedure, Baikal State University, 11 Lenin St., 664003, Irkutsk, Russian Federation; e-mail: gnatko.ea@gmail.com.

\section{Библиографическое описание статьи}

Гнатко Е. А. Недействительность исполнительных документов и основания признания их таковыми / Е. А. Гнатко // Baikal Research Journal. - 2016. — T. 7, № 6. - DOI: 10.17150/2411-6262.2016.7(6).22.

\section{Reference to article}

Gnatko E. A. Invalidity of executive documents and grounds of recognizing them as such. Baikal Research Journal, 2016, vol. 7, no. 6. DOI: 10.17150/2411-6262.2016.7(6).22. (In Russian).

\section{Baikal Research Journal}

